\title{
Interactions between endocarditis-derived Streptococcus gallolyticus subsp. gallolyticus isolates and human endothelial cells
}

\author{
Tanja Vollmer, Dennis Hinse, Knut Kleesiek, Jens Dreier ${ }^{*}$
}

\begin{abstract}
Background: Streptococcus gallolyticus subsp. gallolyticus is an important causative agent of infective endocarditis (IE) but the knowledge on virulence factors is limited and the pathogenesis of the infection is poorly understood. In the present study, we established an experimental in vitro IE cell culture model using EA.hy926 and HUVEC cells to investigate the adhesion and invasion characteristics of 23 Streptococcus gallolyticus subsp. gallolyticus strains from different origins (human IE-derived isolates, other human clinical isolates, animal isolates). Adhesion to eight components of the extracellular matrix (ECM) and the ability to form biofilms in vitro was examined in order to reveal features of S. gallolyticus subsp. gallolyticus endothelial infection. In addition, the strains were analyzed for the presence of the three virulence factors gtf, pilB, and fimB by PCR.

Results: The adherence to and invasion characteristics of the examined S. gallolyticus subsp. gallolyticus strains to the endothelial cell line EA.hy926 differ significantly among themselves. In contrast, the usage of three different in vitro models (EA.hy926 cells, primary endothelial cells (HUVECs), mechanical stretched cells) revealed no differences regarding the adherence to and invasion characteristics of different strains. Adherence to the ECM proteins collagen I, II and IV revealed the highest values, followed by fibrinogen, tenascin and laminin. Moreover, a strong correlation was observed in binding to these proteins by the analyzed strains. All strains show the capability to adhere to polystyrole surfaces and form biofilms. We further confirmed the presence of the genes of two known virulence factors (fimB: all strains, gtf: 19 of 23 strains) and demonstrated the presence of the gene of one new putative virulence factor (pilB: 9 of 23 strains) by PCR.

Conclusion: Our study provides the first description of S. gallolyticus subsp. gallolyticus adhesion and invasion of human endothelial cells, revealing important initial information of strain variability, behaviour and characteristics of this as yet barely analyzed pathogen.
\end{abstract}

\section{Background}

Viridans streptococci are the most important pathogens responsible for native valve infective endocarditis (IE) in non-drug-addicted patients [1]. However, Streptococcus gallolyticus subsp. gallolyticus, formerly referred to as Streptococcus bovis biotype I, a member of group D streptococci, was estimated to be the causative agent in $24 \%$ of streptococcal endocarditis [2]. S. gallolyticus subsp. gallolyticus belongs to the $S$. bovis-complex including different species frequently isolated from humans and animals (S. bovis, S. gallolyticus, S.

\footnotetext{
* Correspondence: jdreier@hdz-nrw.de

Institut für Laboratoriums- und Transfusionsmedizin, Herz- und

Diabeteszentrum Nordrhein-Westfalen, Bad Oeynhausen, Germany
}

infantarius, S. equinus, S. alactolyticus). The taxonomic classification of this group of streptococci was often revised. However, at the beginning of this decade, Schlegel et al. proposed the reclassification of S. bovis biotype I as S. gallolyticus subsp. gallolyticus based on genetic, physiologic and phylogenetic perceptions [3], which was recently confirmed in a large comprehensive study [4]. Therefore, the highest priority regarding the clinical significance must refer to S. gallolyticus subsp. gallolyticus instead of S. bovis. Particularly in Southern Europe, the proportion of endocarditis caused by group D streptococci increased over the recent years [5,6]. Hoen et al. documented that 58\% (France), 9.4\% (other European countries) and $16.7 \%$ (USA) of streptococcal IE cases 
were caused by S. bovis [6]. S. gallolyticus subsp. gallolyticus is a normal inhabitant of the human gastrointestinal tract and numerous reports, referring to S. bovis, demonstrated an association between IE and gastrointestinal neoplasia, which were in most cases colonic adenoma or carcinoma [7-9] as well as liver disease [10,11]. Either the underlying colonic disease or an altered hepatic function may promote the bacterial translocation during the initial phase of infection [10].

Pathogenesis and several virulence factors have been examined for viridans streptococci, yet the knowledge of similar mechanisms for S. gallolyticus subsp. gallolyticus is limited. Studies examined the adhesion of animal isolates from pigeons to immobilized matrix proteins [12], and characterized virulence-associated surface proteins [13-15]. Recently, Sillanpää et al. observed a difference in adherence to distinct host extracellular matrix (ECM) proteins of endocarditis-derived S. gallolyticus subsp. gallolyticus isolates [2]. Until now, analogue mechanisms of human isolates regarding the adhesion to or invasion of endothelial cells, as well as defined virulence genes are unknown. Viridans streptococci have been shown to adhere to human endothelial cells in vitro $[16,17]$ and numerous host cell factors and bacterial components have been identified as possible virulence factor candidates in other streptococci [18]. For example, a group of streptococcal genes encoding several adhesins (fimA, $f i m B, s s a B, s c a A, p s a A$ ) play important roles in the development of IE [19-21]. It has also been shown that pilB contributes to adherence to endothelial cells in groupB streptococci and over-expression leads to increased virulence in rats [22,23].

Glycosyltransferases (gtf), which are responsible for the synthesis of glucans, are known to be major cell surface proteins involved in adherence of Streptococcus gordonii to human umbilical vein endothelial cells (HUVECs) in vitro [24]. Glycosyltransferases are further involved in the adhesion to human endothelial cells [24] and modulate cellular cytokine induction in IE [25,26]. Biofilm formation in vitro is also strongly influenced by the amount of Gtf produced by S. mutans $[27,28]$. The role of biofilm formation in IE remains open, with some studies reporting a lack of association $[29,30]$ and other studies proposing a considerable importance [31]. Endothelial matrix proteins, such as collagen, fibronectin, vitronectin, fibrinogen and laminin, have also been shown to serve as receptors for bacterial surface proteins which promote bacterial adherence to host cells [32-37].

In the present study, an in vitro cell culture model was established to analyze the capability of human S. gallolyticus subsp. gallolyticus endocarditis isolates to adhere to and invade endothelial cells in comparison to nonendocarditis associated strains. Furthermore, adherence to immobilized ECM proteins and the ability to form biofilms in vitro was examined to determine a possible association with endocarditis virulence. Isolates were further analyzed for the presence of the virulence associated genes fimB, gtf and pilB.

\section{Methods}

\section{Bacterial strains and growth conditions}

Bacterial strains listed in Table 1 were obtained from the American Type Culture Collection (ATCC, LGC Promochem GmbH, Wesel, Germany), the Deutsche Sammlung von Mikroorganismen und Zellkulturen GmbH (DSMZ, Braunschweig, Germany) or were previously isolated from patients' specimens at our hospital. All clinical isolates used in this study were characterized in our microbiological laboratory by standard methods. In addition, molecular genetic strain identification was performed by sequencing analysis of the superoxide-dismutase gene $(\operatorname{sod} A)$ as described previously [38]. Bacteria were grown on tryptone soya (TS) or brain heart infusion (BHI) agar plates (Oxoid Ltd., Cambridge, UK) and isolated colonies were used as inocula in TS or BHI medium. Determination of the bacterial titer was performed by plating on TS agar. For simplification of readability, S. gallolyticus subsp. gallolyticus is consecutively abbreviated to $S$. gallolyticus.

\section{Cell culture}

EA.hy926 cells were derived from the ATCC (Manassas, USA) and cultured in Dulbecco's modified essential medium (DMEM, Gibco, Invitrogen, Karlsruhe, Germany) containing $1 \% \mathrm{~L}$-glutamine $(200 \mathrm{mM})$, supplemented with $10 \%$ fetal calve serum (Biowest, Nuaillé, France) and $1 \%$ antibiotic/antimycotic solution (100x, Biowest). Cells were grown at $5 \% \mathrm{CO}_{2}$ and $37^{\circ} \mathrm{C}$ in a humidified atmosphere and were used before passage 10 for all experiments. Cryopreserved pooled HUVECs were purchased from Lonza (Basel, Switzerland) and grown routinely in EGM-2 medium (EGM-2 BulletKit, Lonza) at $5 \% \mathrm{CO}_{2}$ and $37^{\circ} \mathrm{C}$ in a humified atmosphere. Cell culture dishes were previously coated with collagen I (Sigma, Steinheim, Germany). Cells were utilized before passage five for all experiments. EA.hy926 and HUVEC cells were detached using 10\% trypsin-EDTA (Lonza). For the adherence and invasion assays, cells were transferred after trypsination to 6-well culture plates and cultivated to confluence. Before infection with bacteria, cells were washed three times with Dulbecco's phosphate buffered saline (DPBS, Gibco).

\section{Cell adherence and invasion assay}

The assay was performed as described previously with some modifications [39,40]. Briefly, bacterial cultures were harvested at late-log phase, washed once with 
Table 1 List of strains analyzed in this study with source, sodA GenBank accession numbers, distribution of virulence gene sequences detected by PCR and occurrence of intestinal abnormalities.

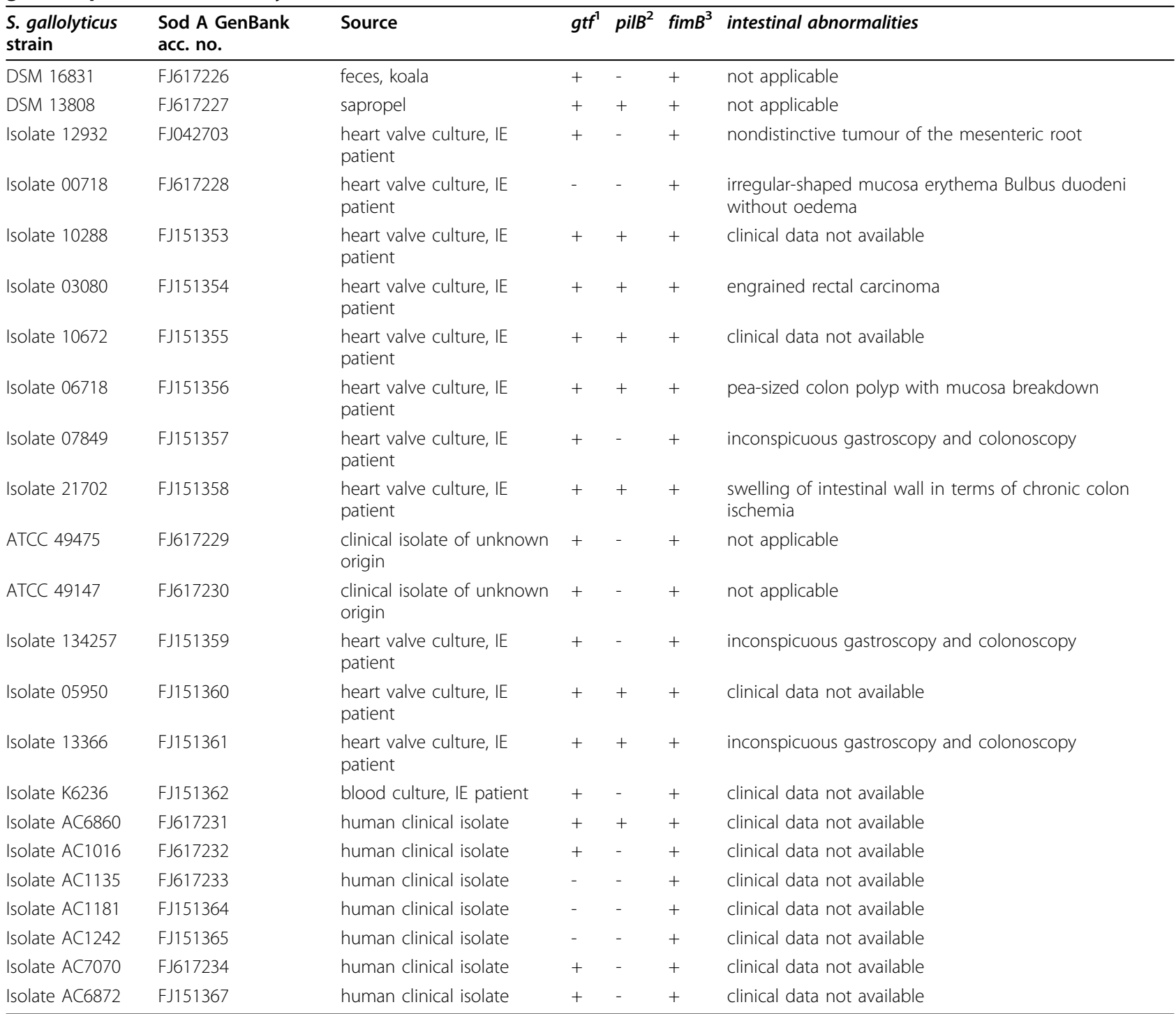

${ }^{1}$ gene coding for glycosyltransferase, ${ }^{2}$ gene coding for pilus-associated protein,

${ }^{3}$ gene coding for fibrinogen-binding protein

DPBS and diluted in fresh cell culture medium without antibiotics. To analyze dose-dependent effects on adhesion and invasion, two millilitres of bacterial suspensions with inocula between $10^{2}$ and $10^{7} \mathrm{CFU} / \mathrm{mL}$ were added to each well containing a monolayer of EA.hy926 or HUVEC cells, respectively. For the comparison of adhesion and invasion efficacy of different S. gallolyticus strains, cells were infected with $1-9 \times 10^{5} \mathrm{CFU} / \mathrm{mL}$. The 6 -well plates were incubated for $2 \mathrm{~h}$ at $37^{\circ} \mathrm{C}$ and $5 \% \mathrm{CO}_{2}$ to facilitate cell infection. For the adherence assay, the cell monolayer was washed five times with DPBS, and endothelial cells were trypsinized and lysed with $1 \mathrm{~mL} \mathrm{10 \%} \mathrm{Trypsin-EDTA} \mathrm{in} \mathrm{distilled} \mathrm{water.} \mathrm{Tryp-}$ sin-reaction was stopped with an equal volume of cell culture medium without antibiotics. $100 \mu \mathrm{L}$ from each well were plated onto TS agar and incubated overnight at $37^{\circ} \mathrm{C}$. For the invasion assay, the monolayer was washed three times with DPBS. Two millilitres of cell culture medium supplemented with $1 \%$ antibiotic/antimycotic solution and $100 \mu \mathrm{g} / \mathrm{mL}$ gentamicin (Gibco) were added to each well. The 6 -well plates were incubated for another $2 \mathrm{~h}$ at $37^{\circ} \mathrm{C}$ and $5 \% \mathrm{CO}_{2}$ to kill extracellular and surface-adherent bacteria. Afterwards, the monolayers were washed three times with DPBS and bacteria were quantified as described for the adherence assay. Assays were performed in duplicate and repeated twice. For comparative reasons, isolate 21702 was used as an internal assay control in every assay. Antibiotic 
efficacy of the invasion assay was tested for all strains with concentrations of $10^{7} \mathrm{CFU} / \mathrm{mL}$ in pure cell culture medium, confirming that no viable bacteria were present after $2 \mathrm{~h}$ incubation (data not shown).

\section{Mechanical stretch}

Cultures of EA.hy926 were subjected to cyclic tension using a FlexCell vacuum system (FlexCell, Dunn Laboratories, Hillsborough, USA). Cells were cultured on BioFlex culture plates (FlexCell) coated with collagen I in a humidified atmosphere with $5 \% \mathrm{CO}_{2}$ at $37^{\circ} \mathrm{C}$ for $72 \mathrm{~h}$. Afterwards cultures were stretched by $10 \%$ with a frequency of $1 \mathrm{~Hz}$ in a square wave pattern for another 24 h. EA.hy926 from the same preparation and cultured without mechanical stretch were used as controls. Stretched cells and controls were infected immediately after completion of mechanical stretch as described above.

\section{Biofilm assay}

The biofilm assay used in this study was performed as described previously [30] with the following modifications: absorbance was measured using the GENios Plate Reader (Tecan Deutschland GmbH, Crailsheim, Germany) at $450 \mathrm{~nm}$ (total bacterial growth) and $550 \mathrm{~nm}$ (crystal violet $(\mathrm{CV})$, biofilm formation). Each strain was assayed in quintuplicate.

\section{ECM assay}

96 well microtiter plates were coated with $10 \mu \mathrm{g} / \mathrm{mL}$ fibrinogen (human plasma, Sigma). Microtiter plates precoated with collagen I, collagen II, collagen IV, fibronectin, laminin, tenascin and vitronectin were purchased from Chemicon (Millipore, Schwalbach, Germany). Wells coated with BSA were used as negative controls and values were subtracted. Late-log-phase cultures of bacteria were inoculated into $100 \mu \mathrm{L}$ BHI medium (Oxoid) and incubated on pre-coated wells without agitation for $2 \mathrm{~h}$ at $37^{\circ} \mathrm{C}$. Subsequently, wells were washed twice with DPBS and dried for $20 \mathrm{~min}$ at $60^{\circ} \mathrm{C}$. In parallel, bacteria were plated onto BHI agar and incubated overnight at $37^{\circ} \mathrm{C}$. Attached bacteria were stained with $100 \mu \mathrm{L}$ of $0.4 \% \mathrm{CV}$ at room temperature for $45 \mathrm{~min}$. Wells were rinsed five times with PBS and air dried. CV was solubilized in $100 \mu \mathrm{L}$ ethanol (99\%), and the absorbance was measured at $550 \mathrm{~nm}$. Each strain was assayed in quadruplicate for the different ECM proteins.

\section{PCR analysis}

Bacteria were harvested from overnight grown cultures and bacterial DNA was extracted using the QIAamp DNA Blood Kit (protocol D, Qiagen, Hilden, Germany) according to the manufacturer's instructions. PCR primers were designed to amplify the known virulence factors of S. gallolyticus fimB and gtf and to amplify a homolog of the pilB gene identified in S. suis (Table 2). DNA amplification was carried out in $0.2 \mathrm{~mL}$ tubes containing $45 \mu \mathrm{L}$ reaction mix and $5 \mu \mathrm{L}$ DNA extract. The reaction mix consisted of $1 \times$ HotMaster Taq buffer including $2.5 \mathrm{mM} \mathrm{MgCl}_{2}, 200 \mu \mathrm{M}$ of each dNTP, 100 $\mathrm{nM}$ of each primer and 1.25 $\mathrm{U}$ of HotMaster Taq DNA polymerase (5 Prime, Inc., Gaithersburg, USA). The PCR conditions were as follows: initial denaturation at $94^{\circ} \mathrm{C}$ for $5 \mathrm{~min}$, followed by 30 cycles of denaturation at $95^{\circ} \mathrm{C}$ for $30 \mathrm{~s}$, PCR-product specific annealing temperature (Table 2) for $60 \mathrm{~s}$ and extension at $72^{\circ} \mathrm{C}$ for $60 \mathrm{~s}$, followed by a final elongation for $10 \mathrm{~min}$ at $72^{\circ} \mathrm{C}$. PCR products were sequenced for identification as described previously [41].

\section{Statistical analysis}

Statistical analysis was performed using One-wayANOVA, the Mann-Whitney-U-test and the student's ttest where appropriate. Multiple testing correction was performed using the Bonferroni method. Normality testing of all data sets for Gaussian distribution was performed using the Kolmogorov-Smirnov test. We used Spearman correlation coefficients to assess correlations between variables. $\mathrm{P}$ values $<0.01$ were considered significant. All values are given as mean values $( \pm$ SD). Statistical analysis was performed using GraphPad Prism 4.0 software (GraphPad Software, San Diego, CA, USA).

\section{Results}

Identification of virulence genes and occurrence of intestinal abnormalities

All strains analyzed in this study were identified as $S$. gallolyticus by sequencing analysis of the sodA gene (GenBank accession no. Table 1). Table 1 displays the distribution of the analyzed $S$. gallolyticus virulence genes fimB, gtf and pilB among 23 different strains. The known virulence gene $\operatorname{fim} B$ was detected in all analyzed strains, whereas four strains showed no positive PCR signal for $g t f$. The occurrence of a partial sequence homolog of the pilB gene, originally identified in S. suis, was proven in 9 strains of S. gallolyticus (GenBank accession no. for S. gallolyticus partial pilB sequence: FJ555059). Sequencing analysis confirmed the gene as pilB with a high similarity of $98 \%$ to $S$. suis pilB. PCR screening results were confirmed by Southern-Blot analysis with total genomic DNA and Digoxigenin-labeled PCR products (data not shown).

Analysis of the corresponding patient information of eight isolates revealed two patients exhibiting colonic malignancies, three patients with intestinal abnormalities and three patients without evidence of intestinal abnormalities (Table 1). For the other eleven human clinical isolates, patient data was not available because 
Table 2 Primer sequences and PCR conditions.

\begin{tabular}{|c|c|c|c|c|c|}
\hline Primer & Oligonucleotide sequence $\left(5^{\prime}-3^{\prime}\right)$ & Nucleotide positions* & Annealing temperature & Amplicon length & Genbank accession no. \\
\hline fimB-550F & GGTAAGTGATGGTATTGATGTC & $550-571$ & 45 & 347 & AY321316 \\
\hline fimB-875R & GTGTTCCTTCTTCCTCAGTATT & 875-896 & & & \\
\hline gtf-F & GGTGAGACTTGGGTTGATTC & $2049-2068$ & 54 & 496 & AB292595 \\
\hline gtf-R & GCTCTGCTTGAACAACTGGA & $2525-2544$ & & & \\
\hline pilB-385F & AAGGGACGAGGGCTCTAC & $120017-120034$ & 58 & 339 & СР000408 \\
\hline pilB-722R & ACCCAATTCCAACATACG & $120373-120356$ & & & \\
\hline
\end{tabular}

*positions according to the respective Genbank accession no.

isolates were obtained from other institutes and repeatedly characterized in our microbiological laboratory.

\section{Adhesion to and invasion of EA.hy926 cells}

All strains started to grow after $3 \mathrm{~h}$ of incubation in DMEM at $37^{\circ} \mathrm{C}$ and $5 \% \mathrm{CO}_{2}$ at the earliest (data not shown). Therefore, incubation time for adhesion was determined to $2 \mathrm{~h}$ to avoid false-high titers as a result of bacterial growth kinetics. Three strains representing different adherence and invasion potentials, namely strain DSM 16831 (low adhesion, no invasion), isolate 21702 (intermediate adhesion and invasion) and isolate 05950 (high adhesion and invasion), were chosen to exemplify the dose-dependent effects on adhesion and invasion to EA.hy926 cells (Fig. 1). The proportion of adhesive and invasive bacteria did not increase using higher bacterial concentrations, with both, the adhesiveness and the invasiveness of the different bacteria showing a linear progress. Remarkably, strain DSM 16831 did not have the potential to invade cells, even when higher bacterial concentrations were used for infection. Subsequently, all S. gallolyticus strains were compared regarding their adhesion and invasion characteristics to EA.hy926 cells (Fig. 2). As a result of the observed linear progress and for strain comparability the initial inocula were calculated to $1 \times 10^{5} \mathrm{CFU} / \mathrm{mL}$, and consequently adhesion and invasion values were factorized. Generally, all the $S$. gallolyticus strains analyzed were able to adhere to EA. hy926 endothelial cells (range $10^{3}-10^{4}$ recovered CFU/ $\mathrm{mL}$ ) and significant differences were observed among the investigated strains (repeated measures anova, $P<$ 0.0001). Consideration of the individual strains revealed that isolates 13366, K6236 and AC1016 presented the most frequently significances (Fig. 2). With the exception of strain DSM 16831, which was excluded in further statistical analysis regarding invasion characteristics, all S. gallolyticus strains also had the capacity to invade EA.hy926 cells (range $10^{1}-10^{3}$ recovered CFU/ $\mathrm{mL}$ ) with significant differences (repeated measures anova, $P<0.0001$ ). A closer look on variation between individual strains disclosed, that the potential of invasion of the two strains DSM 13808 and isolate 05950 demonstrated numerous significances overall (DSM 13808: 17 strains, $P<0.001$; isolate 05950: five strains, $P<0.001$ and seven strains $P<0.01$, Fig. 2). Correlation analysis of adherence and invasion showed a strong correlation for all strains (Spearman rank correlation coefficient $\mathrm{r}=$ $0.673, P=0.0003)$. A considerable difference in the adherence or invasion potential of endocarditis isolates and reference strains was not observed. However, five strains illustrate noticeable characteristics (Fig. 2). Strain DSM 16831 has a considerably low ability of adherence and no ability of invasion. In comparison to isolates characterized as common, isolate AC6827 has a low adherence and invasion, whereas isolate 134257 exposed only a low adherence. Strain DSM 13808 and isolate 05950 revealed standard adhesive characteristics but the invasion capacity was considerably higher compared to the other isolates. Correlation analysis of adherence to or invasion of endothelial cells and the number of present virulence genes revealed no correlation: (a) three virulence genes versus two virulence genes: $P_{\text {adhesion }}=$ $0.35, P_{\text {invasion }}=0.12$, (b) three virulence genes versus one virulence gene: $P_{\text {adhesion }}=0.08, P_{\text {invasion }}=0.19$ and (c) two virulence genes versus one virulence gene: $P_{\text {adhesion }}=0.27, P_{\text {invasion }}=0.81$.

Influence of cell type and cell condition on the adherence and invasion characteristics

Fig. 3 shows the adherence to and invasion of EA.hy926 and HUVECs for six bacterial strains with different adhesion and invasion potentials. The comparison of the two different cell types revealed no discrepancy between adhesion and invasion $(P>0.01)$. Therefore, the cell line EA.hy926 was chosen for further studies of S. gallolyticus infection of endothelial cells. As shown in Fig. 3, the adherence and invasion characteristics of S. gallolyticus to EA.hy926 are likewise comparable between mechanical stretched and untreated cells. However, isolates 13366, 05950, 49147 and 06718 show the tendency of a marginally decreased invasion to mechanical stretched cells.

\section{Binding to ECM proteins and biofilm formation}

For evaluation of the ability of S. gallolyticus strains to adhere to host ECM proteins, we analyzed adherence to 


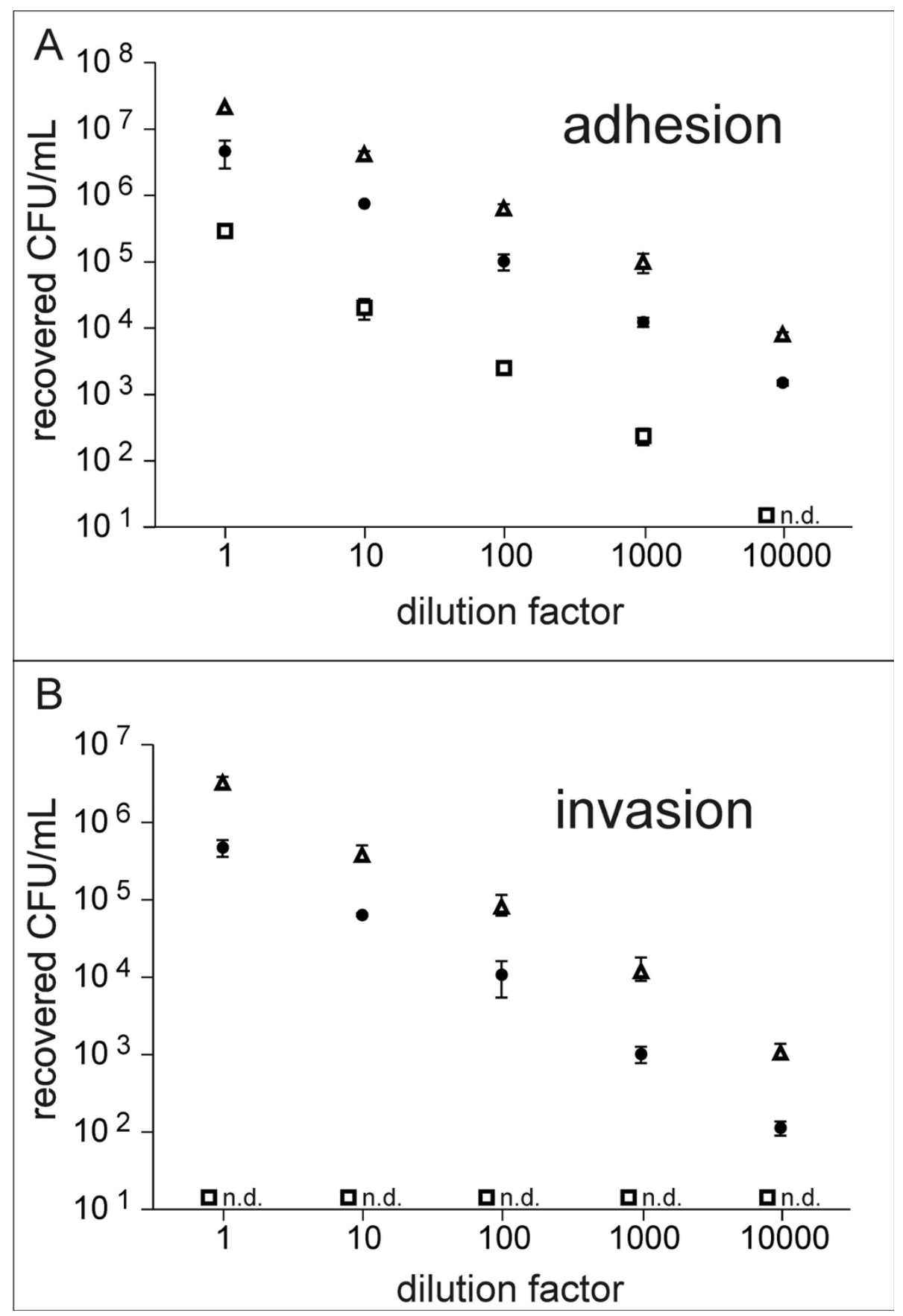

Figure 1 Dose response analysis of S. gallolyticus adhesion to and invasion of EA.hy926 cells. (A) Adhesion, (B) Invasion. Cells were incubated with decreasing concentrations of three different S. gallolyticus strains (white triangle: isolate 05950, black dot: isolate 21702, white square: DSM 16831), as described in Material and Methods. Error bars indicate standard deviations, n.d.: not detectable.

collagen types I, II, IV, fibronectin, laminin, tenascin, vitronectin and fibrinogen (Fig. 4). Adherent bacteria were stained with $\mathrm{CV}$, and parallel plating onto BHI agar confirmed the initial bacterial titer to $10^{8} \mathrm{CFU} / \mathrm{mL}$ for all 23 strains tested. After correction with BSA negative control values, values of $\mathrm{OD}_{550}>0.1$ were considered adherent. Mean values of the three different collagen types did not differ significantly. Adherence to collagen I showed the highest values (mean 0.53 $( \pm 0.28)$ ), followed by collagen II (mean $0.45( \pm 0.27)$ ), collagen IV (mean $0.38( \pm 0.24)$ ), fibrinogen (mean 0.37 $( \pm 0.52))$, tenascin $($ mean $0.25( \pm 0.21))$ and laminin 


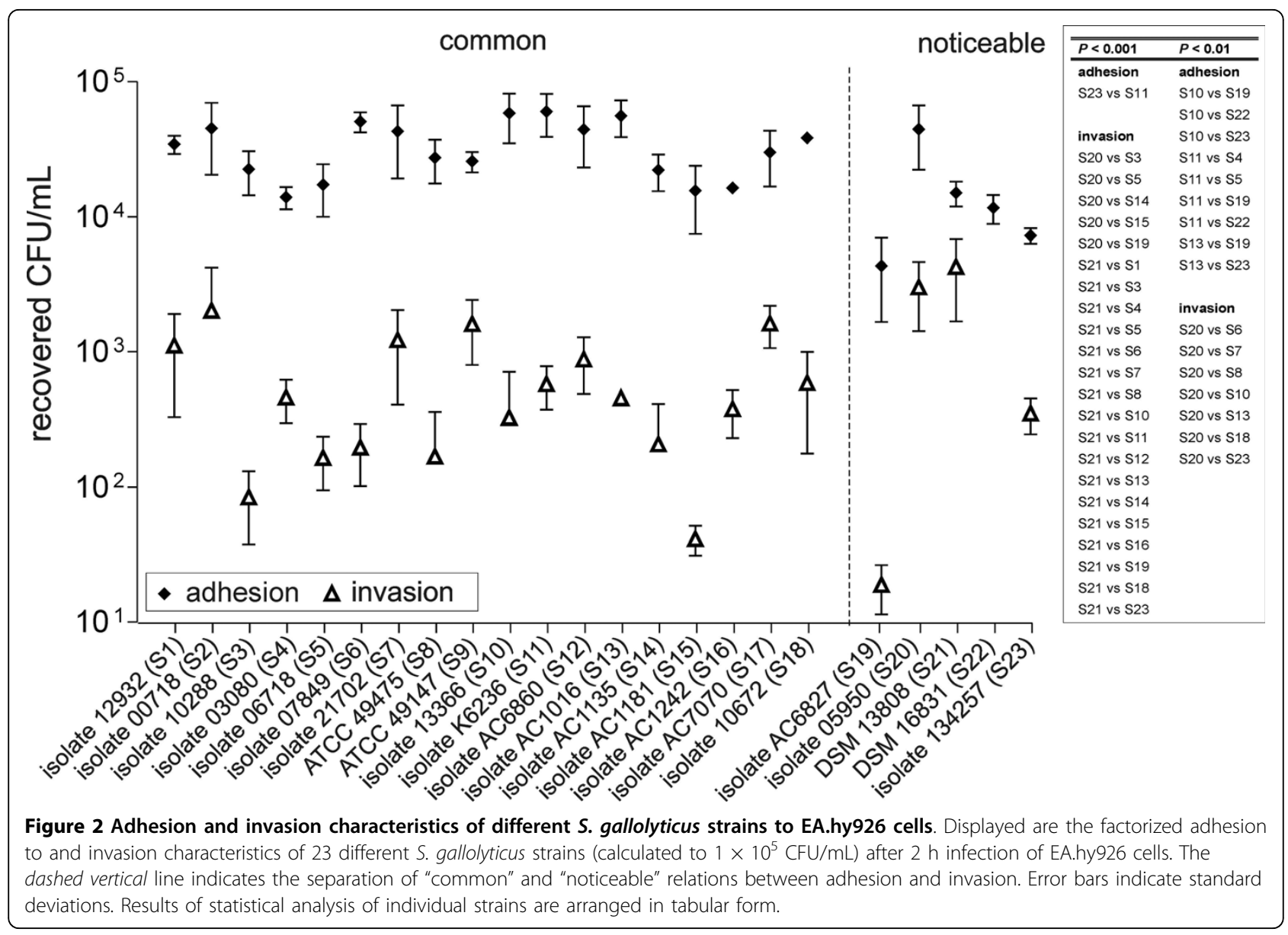

(mean $0.20( \pm 0.19))$. Accordingly, the proportion of non-adherent strains increased almost in this order. One strain was unable to adhere to collagen II and IV, whereas five strains did not adhere to fibrinogen, and seven strains did not adhere to laminin or tenascin. Binding to fibronectin and vitronectin revealed the highest proportion of non-adherent strains (fibronectin: $\mathrm{n}=$ 16, vitronectin: $\mathrm{n}=18$ ) and the observed adherence was relatively low. Individual strain correlation analysis between adherence to endothelial cells and ECM proteins showed no correlation. In contrast, analysis of the adherence of different ECM proteins showed a strong correlation $(P<0.0001)$ for the following nine protein combinations: (a) collagen I versus collagen II, IV, laminin and tenascin, respectively; (b) collagen II versus collagen IV, laminin and tenascin, respectively; (c) collagen IV versus tenascin and (d) laminin versus tenascin (Fig. 4). A correlation of moderate strength was found for the protein combination collagen IV and laminin ( $\mathrm{P}<$ 0.001 ). No correlation was observed for protein combinations including fibronectin, vitronectin or fibrinogen. The ability of adherence to ECM proteins showed a tendency to cluster in certain isolates, e.g. strains with high efficiency of binding to the three different collagen types also showed a strong adherence to laminin and tenascin. Two strains exhibited a considerably higher adherence; isolate AC1181 had a high adherence to collagen I/II/ IV, laminin and tenascin, whereas isolate AC7070 had a high adherence to fibrinogen, vitronectin and fibronectin.

The analysis of biofilm formation demonstrated that all strains have the capability to adhere to polystyrene surfaces and form biofilms (Fig. 4). Isolates 10672, AC1135 and strain DSM 16831 revealed the highest biofilm formation; remarkably, strain DSM 16831 had no capacity to invade cells. Correlation analysis of adherence to or invasion of endothelial cells and biofilm formation revealed no correlation. Additionally, no correlation was found between adherence to different ECM proteins and biofilm formation.

\section{Discussion and Conclusions}

S. gallolyticus is an important pathogen with an underestimated relevance causing IE. The frequent changes in the taxonomy resulted in an inadequate or incorrect identification of the causative pathogens, because non- 

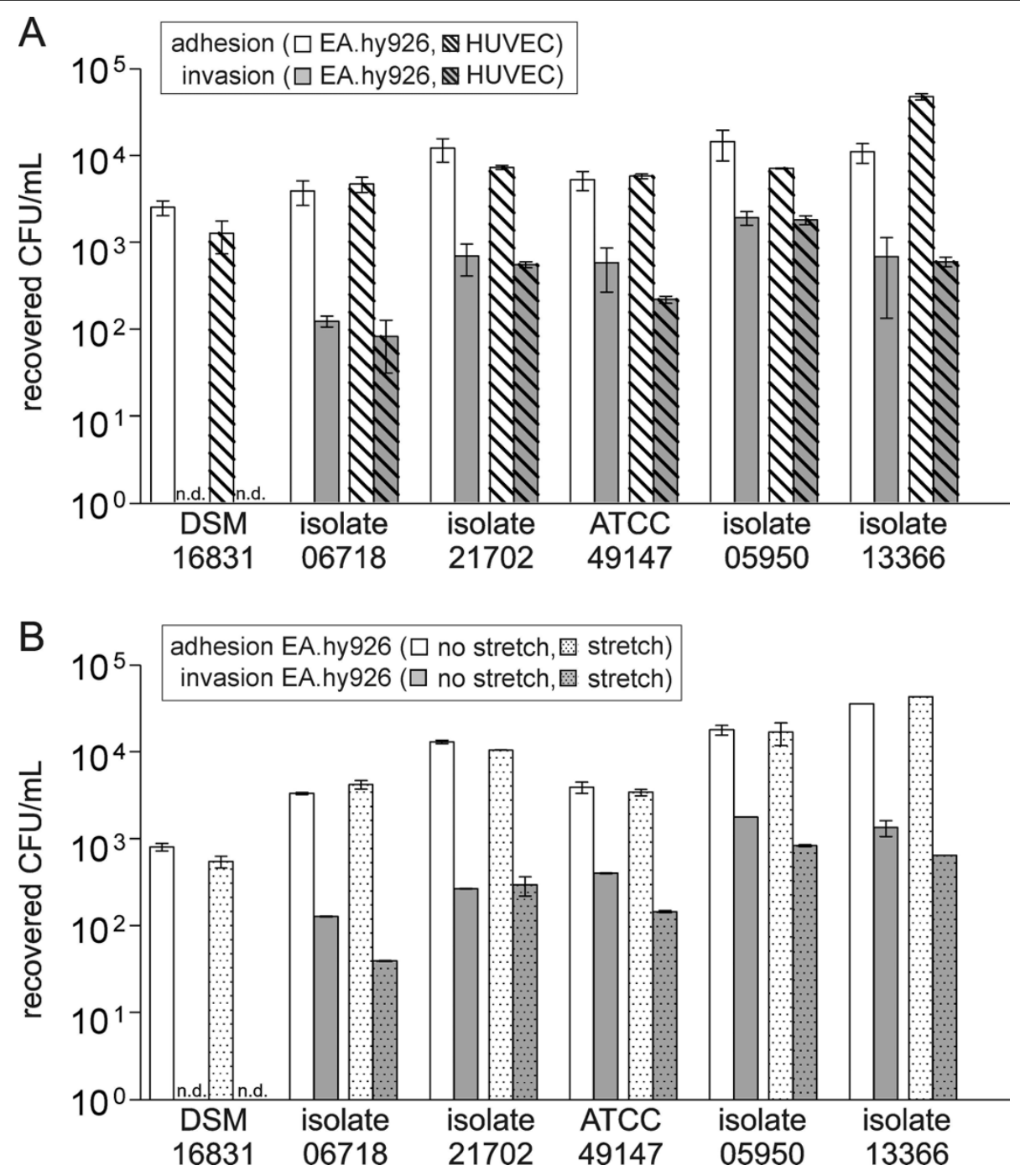

Figure 3 Influence of cell type (EA.hy926/HUVEC) and cell condition (stressed/non-stressed) on the adherence and invasion characteristics of S. gallolyticus. (A) Adhesion to and invasion of endothelial cell lines EA.hy926 and HUVECs after infection with $1-9 \times 10^{5}$ CFU/mL of different S. gallolyticus strains. (B) S. gallolyticus strain's adhesion to and invasion of EA.hy 926 with and without mechanical stretch 24 $\mathrm{h}$ prior to infection with $1-9 \times 10^{5} \mathrm{CFU} / \mathrm{mL}$ bacteria. Results were determined after a $2 \mathrm{~h}$ exposure followed by additional $2 \mathrm{~h}$ incubation in the presence of antibiotics. n.d.: not detectable.

experts were often not aware of the new nomenclature (e.g. [42]). In contrast to other streptococci, little is known about virulence factors and pathogenesis. The adherence of circulating bacteria to damaged heart tissues and subsequent colonization and persistence of bacteria are the crucial factors in streptococcal IE. The prevention of tissue colonization, with special attention to targeting therapy against ECM-binding, potentially provides a promising alternative in human medicine [43]. Therefore, we analyzed the factors which contribute to S. gallolyticus adhesion and invasion in IE using an experimental in vitro cell culture model. Investigation of the adhesion to ECM proteins identified or confirmed putative adhesive sites on the endothelial cell surface.
Additionally, virulence factors were detected and biofilm formation was analyzed in order to identify different strain characteristics.

Most S. gallolyticus strains tested in this study adhere to and invade endothelial cells. The diversity in adhesion and invasion characteristics appears considerably higher for invasion. Strain DSM 16831 exclusively demonstrated no invasive capability. Invasion was also not induced using higher concentrations of bacteria, usage of primary endothelial cells or mechanical stretched cells. In contrast, strain DSM 13808 present a considerably high invasion. The distinct behaviour of these two strains may be due to the fact that they were the only strains tested that were isolated from non-human 


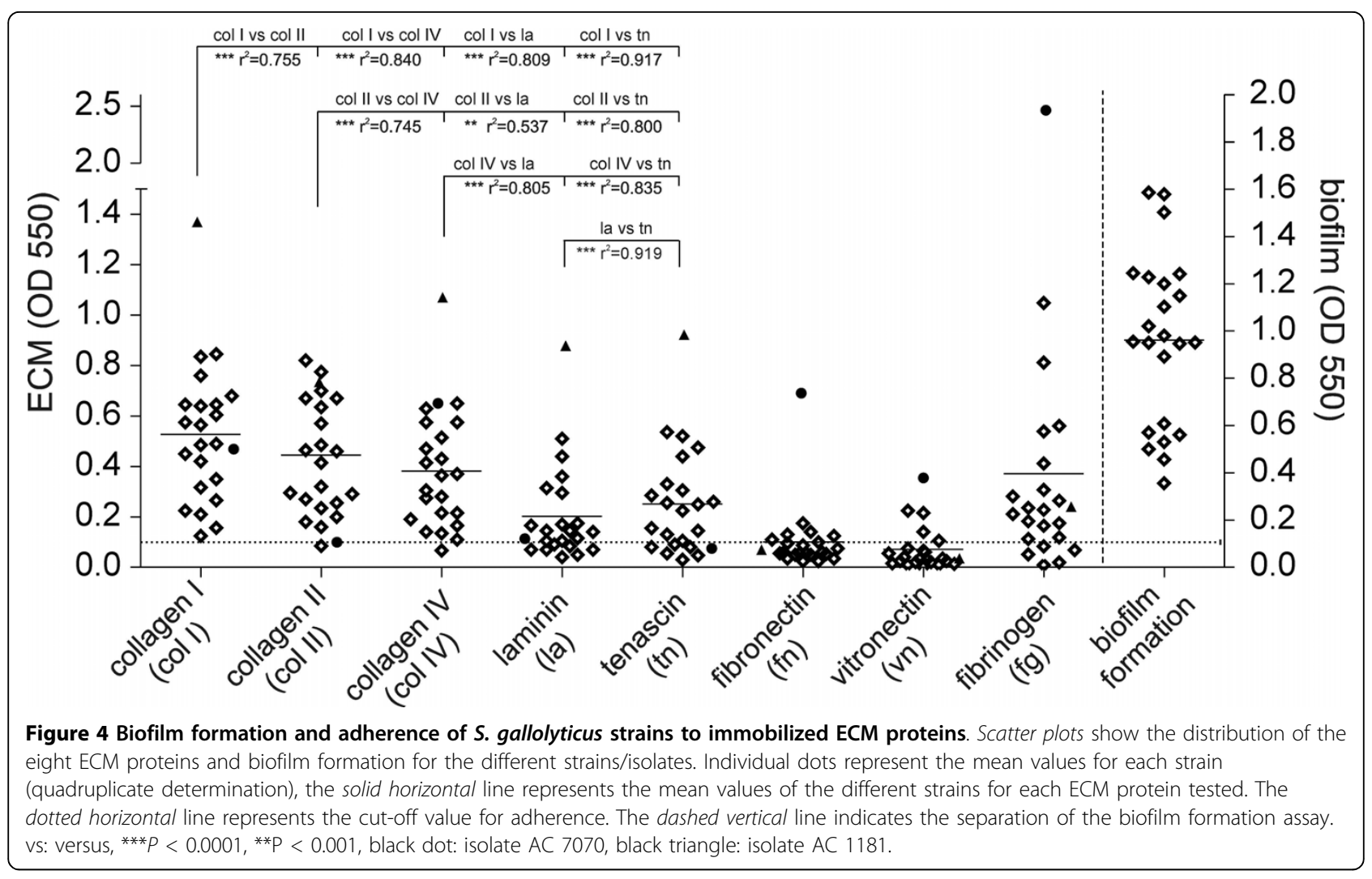

sources. In general, the observed differences may reflect distinctions in the bacterial equipment with virulence factors or gene expression of virulence factors. We have shown that isolate represent a different distribution of the virulence-associated genes $g t f$, fimB and pilB. However, the presence of a putative virulence gene does not necessarily indicate expression. For example, Stipp et al. observed variability at different phases of planktonic growth in $g t f B$ and $g t f C$ gene expression [44]. Furthermore, the gene integrity has to be proven. To correlate virulence with the expression of $g t f$, fimB and pilB, these factors have to be deleted by the construction of knockout mutants to determine difference in the ability to form biofilms, the adherence to and invasion of host cells and the adherence to ECM proteins. This will show the impact of these factors on binding to host cells and most likely correlate with the bacterial potential to cause IE. In addition, the determined virulence factors reflected only a small proportion of the presumably high quantity of possible virulence factors in S. gallolyticus. Accordingly, the absence of a correlation between the potential to adhere to as well as to invade cells and the number of the existing putative virulence genes most likely could also be explained by these reasons.

The role of biofilm formation in IE remains ambiguous. Several studies demonstrated an association between biofilm formation and streptococcal IE [45-47], whereas another study indicated that the ability to form biofilms in vitro is not associated with endocarditis virulence [30]. The results of our study support the lack of association between biofilm formation and adherence to or invasion of endothelial cells and adherence to ECM proteins.

Most IE patients have valve abnormalities, resulting in the exposure of ECM proteins, the production of tissue factor and the deposition of fibrin and platelets promoting bacterial colonization. Streptococcal adherence to endothelial matrix proteins has previously been shown to be an important factor for the infection of host tissues [32-37,48]. Recently, Sillanpää et al. analyzed endocarditis-derived human isolates of $S$. gallolyticus and, according to the results obtained in our study, binding to collagen I was found to be the most common phenotype, followed by collagen type IV, fibrinogen and fibronectin [2]. In contrast, both studies revealed a weak binding to fibronectin, which is contradictory to studies observing a direct connection between adherence to fibronectin and the applicability of $S$. sanguis to induce IE [49]. This observation possibly indicates a different pathogenesis of S. gallolyticus IE. Interestingly, a study of animal isolates of S. gallolyticus revealed no adherence to collagen I [12]. Further analysis of the draft genome sequence of an ECM protein-adherent 
S. gallolyticus strain by Sillanpää et al. revealed 11 predicted LPXTG-type cell-wall-anchored proteins with characteristics of MSCRAMMs (microbial surface components recognizing adhesive matrix molecules), including the "adhesin to collagen of the S. bovis group" ( $a c b)$ gene [50]. Remarkably, a recombinant Acb protein showed high affinity binding to immobilized collagen. Cell surface expression of Acb correlated with the presence of $a c b$ and collagen adherence of different isolates. Therefore, the authors concluded that the high prevalence of this collagen-binding MSCRAMM among $S$. gallolyticus may play an important role in the predominance of this subspecies in $S$. bovis complex endocarditis.

The endothelial cell line EA.hy926 displays highly differentiated characteristics of human vascular endothelial [51] whereas primary endothelial cells such as HUVECs presumably provide the most accurate cell type based reflection of the in vivo situation. However, we observed no difference in the adhesion and invasion characteristics of S. gallolyticus using these two cell lines. Consequently, the usage of endothelial cell lines seems to be an equivalent experimental in vitro model, with the major advantage of easier handling compared to primary cells. Nonetheless, it has to be noted that cell monolayers of either cell lines or primary cells only provide a two-dimensional model, whereas the in vivo situation in tissue is three-dimensional.

The intact endothelium is usually resistant to colonization by streptococci [18]. In the present study, mechanical stress of endothelial monolayer does not increase the proportion of adherent or invasive bacteria. This data is an indication for active colonization of valve tissue by $S$. gallolyticus. However, the results have to be interpreted with caution. We cannot exclude the possibility that mechanical stretch does not significantly increase the degree of stress on the potentially damaged cell monolayer. In addition, monolayers probably do not exhibit a physically intact endothelium since two-dimensional cultivation or contact-inhibition perhaps affected the endothelial cells. Therefore, further studies are warranted to figure out the degree of monolayer integrity and the dimension of cell damage before and after mechanical stretch.

The data of our study demonstrates that there is no evidence for the correlation between adherence to or invasion of endothelial cells, the adherence of bacteria to ECM proteins and biofilm formation. Therefore several other factors have to be investigated to determine their role in the infection of endothelial cells by $S$. gallolyticus isolates. These factors might include the capsule structure [52], interaction with cell surface glycosaminoglycans [53], presence of fimbriae or production of toxins [15]. It has been shown that S. gallolyticus is capable to produce capsular material [15] and the amount of capsule produced most likely influence the capacity to adhere to the cells. Hence, analysis of further pathomechanisms beneath adhesion, invasion and biofilm formation characteristics as well as the identification of further putative virulence genes is crucial for a better understanding of the mechanisms of S. gallolyticus infection. Our future investigations will address the transcriptional analysis of known virulence factors, the identification and characterization of further putative virulence genes by sequencing the whole genome of $S$. gallolyticus and knock-out mutation experiments to determine the influence of individual gene function in the pathogenesis of IE. As a result of the distinct behaviour of the isolates from non-human sources, we will also focus on the comparison of human and animal isolates to further elaborate potential differences in infection mechanisms. The specific clinical association with gastrointestinal neoplasia due to $S$. bovis biotype I or $S$. gallolyticus, respectively [7-9] strongly imply that S. gallolyticus enter the human body via the gastrointestinal tract through sites with decreased intestinal barrier function such as colonic malignancies. Unfortunately, a correlation between the number of existing virulence genes, biofilm formation, invasion and adhesion characteristics with the presence or absence of colonic malignancies can barely be created with the small number of available patient data at present. Indeed, the bacterial translocation is the first important step in the development of IE before colonizing the endothelium, and mechanisms of adherence to and invasion of epithelial cells play an important role during this initial phase of infection. Therefore, our future investigations will also address this important mechanism to potentially disclose clues on specific features of individual S. gallolyticus strains.

In conclusion, this is the first description of S. gallolyticus adhesion to and invasion of human endothelial cells. The established in vitro model provides a convenient system to evaluate differences in the virulence characteristics of different strains. Binding to ECM proteins and biofilm formation provide additional information for strain characterization. The first identification of a possible pilus-associated gene in S. gallolyticus supplemented the so far limited availability of possible virulence factors. This study provides important initial characterization of variability and behaviour of the as yet barely analyzed endocarditis pathogen $S$. gallolyticus.

\section{Abbreviations}

BHI: brain heart infusion; CV: crystal violet; DMEM: Dulbecco's modified essential medium; DPBS: Dulbecco's phosphate buffered saline; ECM: extracellular matrix; HUVECs: human umbilical vein cells; IE: infectious 
endocarditis; MSCRAMMs: microbial surface components recognizing adhesive matrix molecules; TS: tryptone soya.

\section{Acknowledgements}

We thank Sarah L. Kirkby for her linguistic advice. This work was supported by the "Forschungsfoerderung der Medizinischen Fakultaet der RuhrUniversitaet Bochum (FoRUM), Grant F606-2007.

\section{Authors' contributions}

TV carried out the adhesion and invasion studies and drafted the manuscript. DH carried out the molecular genetic studies, the biofilm formation assays and helped to draft the manuscript.

KK conceived and designed the study and revised the manuscript critically for important intellectual content. JD supervised the study and participated in its design and coordination, analyzed and interpreted data and revised the manuscript critically for important intellectual content. All authors read and approved the final manuscript.

Received: 29 May 2009 Accepted: 16 March 2010

Published: 16 March 2010

\section{References}

1. Naber CK, Bauhofer A, Block M, Buerke M, Erbel R, Graninger W, Herrmann M: S2-Leitlinie zur Diagnostik und Therapie der infektiösen Endokarditis. Z Kardiol 2004, 93:1005-1021.

2. Sillanpää J, Nallapareddy SR, Singh KV, Ferraro MJ, Murray BE: Adherence characteristics of endocarditis-derived Streptococcus gallolyticus ssp. gallolyticus (Streptococcus bovis biotype I) isolates to host extracellular matrix proteins. FEMS Microbiol Lett 2008, 289(1):104-109.

3. Schlegel L, Grimont F, Ageron E, Grimont PA, Bouvet A: Reappraisal of the taxonomy of the Streptococcus bovis/Streptococcus equinus complex and related species: description of Streptococcus gallolyticus subsp. gallolyticus subsp. nov., S. gallolyticus subsp. macedonicus subsp. nov. and S. gallolyticus subsp. pasteurianus subsp. nov. Int J Syst Evol Microbiol 2003, 53(Pt 3):631-645.

4. Beck M, Frodl R, Funke G: Comprehensive study of strains previously designated Streptococcus bovis consecutively isolated from human blood cultures and emended description of Streptococcus gallolyticus and Streptococcus infantarius subsp. coli. J Clin Microbiol 2008, 46(9):2966-2972.

5. Tripodi MF, Fortunato R, Utili R, Triassi M, Zarrilli R: Molecular epidemiology of Streptococcus bovis causing endocarditis and bacteraemia in Italian patients. Clin Microbiol Infect 2005, 11(10):814-819.

6. Hoen B, Chirouze C, Cabell CH, Selton-Suty C, Duchene F, Olaison L, Miro JM, Habib G, Abrutyn E, Eykyn S, et al: Emergence of endocarditis due to group $D$ streptococci: findings derived from the merged database of the International Collaboration on Endocarditis. Eur J Clin Microbiol Infect Dis 2005, 24(1):12-16.

7. Klein RS, Recco RA, Catalano MT, Edberg SC, Casey Jl, Steigbigel NH: Association of Streptococcus bovis with carcinoma of the colon. N Engl $J$ Med 1977, 297(15):800-802.

8. Ferrari A, Botrugno I, Bombelli E, Dominioni T, Cavazzi E, Dionigi P: Colonoscopy is mandatory after Streptococcus bovis endocarditis: a lesson still not learned. Case report. World J Surg Oncol 2008, 6:49.

9. Corredoira JC, Alonso MP, Garcia JF, Casariego E, Coira A, Rodriguez A, Pita J, Louzao C, Pombo B, Lopez MJ, et al: Clinical characteristics and significance of Streptococcus salivarius bacteremia and Streptococcus bovis bacteremia: a prospective 16-year study. Eur J Clin Microbiol Infect Dis 2005, 24(4):250-255.

10. Zarkin BA, Lillemoe KD, Cameron $J$, Effron PN, Magnuson TH, Pitt HA: The triad of Streptococcus bovis bacteremia, colonic pathology, and liver disease. Ann Surg 1990, 211(6):786-791, discussion 791-782.

11. Tripodi MF, Adinolfi LE, Ragone E, Durante Mangoni E, Fortunato R, larussi D, Ruggiero G, Utili R: Streptococcus bovis endocarditis and its association with chronic liver disease: an underestimated risk factor. Clin Infect Dis 2004, 38(10):1394-1400.

12. Vanrobaeys M, Haesebrouck F, Ducatelle R, De Herdt P: Adhesion of Streptococcus gallolyticus strains to extracellular matrix proteins. Vet Microbiol 2000, 74(3):273-280

13. Vanrobaeys M, De Herdt P, Haesebrouck F, Ducatelle R, Devriese LA: Secreted antigens as virulence associated markers in Streptococcus bovis strains from pigeons. Vet Microbiol 1996, 53(3-4):339-348.
14. Vanrobaeys M, Haesebrouck F, Ducatelle R, De Herdt P: Identification of virulence associated markers in the cell wall of pigeon Streptococcus gallolyticus strains. Vet Microbiol 2000, 73(4):319-325.

15. Vanrobaeys M, De Herdt P, Charlier G, Ducatelle R, Haesebrouck F: Ultrastructure of surface components of Streptococcus gallolyticus (S. bovis) strains of differing virulence isolated from pigeons. Microbiology 1999, 145:335-342.

16. Stinson MW, Alder S, Kumar S: Invasion and killing of human endothelial cells by viridans group streptococci. Infect Immun 2003, 71(5):2365-2372.

17. Schollin J: Adherence of alpha-hemolytic streptococci to human endocardial, endothelial and buccal cells. Acta Paediatr Scand 1988, 77(5):705-710.

18. Moreillon P, Que YA, Bayer AS: Pathogenesis of streptococcal and staphylococcal endocarditis. Infect Dis Clin North Am 2002, 16(2):297-318.

19. Dargere S, Entenza JM, Verdon R: FimB, a member of the Lral adhesin family, mediates adherence of endocarditis-causing Streptococcus bovis I (S. gallolyticus) to fibrinogen. Intersci Conf Antimicrob Agents Chemother 2003, 43:14-17, abstract B823.

20. Burnette-Curley D, Wells V, Viscount $H$, Munro $C L$, Fenno JC, Fives-Taylor $P$, Macrina FL: FimA, a major virulence factor associated with Streptococcus parasanguis endocarditis. Infect Immun 1995, 63(12):4669-4674.

21. Jenkinson HF: Cell surface protein receptors in oral streptococci. FEMS Microbiol Lett 1994, 121(2):133-140.

22. Maisey HC, Hensler M, Nizet V, Doran KS: Group B streptococcal pilus proteins contribute to adherence to and invasion of brain microvascular endothelial cells. J Bacteriol 2007, 189(4):1464-1467.

23. Maisey HC, Quach D, Hensler ME, Liu GY, Gallo RL, Nizet V, Doran KS: A group $B$ streptococcal pilus protein promotes phagocyte resistance and systemic virulence. Faseb J 2008, 22(6):1715-1724.

24. Vacca-Smith AM, Jones CA, Levine MJ, Stinson MW: Glucosyltransferase mediates adhesion of Streptococcus gordonii to human endothelial cells in vitro. Infect Immun 1994, 62(6):2187-2194.

25. Shun CT, Lu SY, Yeh CY, Chiang CP, Chia JS, Chen JY: Glucosyltransferases of viridans streptococci are modulins of interleukin- 6 induction in infective endocarditis. Infect Immun 2005, 73(6):3261-3270.

26. Yeh CY, Chen JY, Chia JS: Glucosyltransferases of viridans group streptococci modulate interleukin- 6 and adhesion molecule expression in endothelial cells and augment monocytic cell adherence. Infect Immun 2006, 74(2):1273-1283.

27. Mattos-Graner RO, Napimoga MH, Fukushima K, Duncan MJ, Smith DJ: Comparative analysis of Gtf isozyme production and diversity in isolates of Streptococcus mutans with different biofilm growth phenotypes. J Clin Microbiol 2004, 42(10):4586-4592.

28. Biswas S, Biswas I: Regulation of the glucosyltransferase (gtfBC) operon by CovR in Streptococcus mutans. J Bacteriol 2006, 188(3):988-998.

29. Presterl E, Grisold AJ, Reichmann S, Hirschl AM, Georgopoulos A, Graninger W: Viridans streptococci in endocarditis and neutropenic sepsis: biofilm formation and effects of antibiotics. J Antimicrob Chemother 2005, 55(1):45-50.

30. Ge X, Kitten T, Chen Z, Lee SP, Munro CL, Xu P: Identification of Streptococcus sanguinis genes required for biofilm formation and examination of their role in endocarditis virulence. Infect Immun 2008, 76(6):2551-2559.

31. Mohamed JA, Huang W, Nallapareddy SR, Teng F, Murray BE: Influence of origin of isolates, especially endocarditis isolates, and various genes on biofilm formation by Enterococcus faecalis. Infect Immun 2004, 72(6):3658-3663

32. Scheld WM, Strunk RW, Balian G, Calderone RA: Microbial adhesion to fibronectin in vitro correlates with production of endocarditis in rabbits. Proc Soc Exp Biol Med 1985, 180(3):474-482.

33. Nyberg P, Sakai T, Cho KH, Caparon MG, Fassler R, Bjorck L: Interactions with fibronectin attenuate the virulence of Streptococcus pyogenes. Embo J 2004, 23(10):2166-2174.

34. Chhatwal GS, Preissner KT, Müller-Berghaus G, Blobel H: Specific binding of the human S protein (vitronectin) to streptococci, Staphylococcus aureus, and Escherichia coli. Infect Immun 1987, 55(8):1878-1883.

35. Chia JS, Yeh CY, Chen JY: Identification of a fibronectin binding protein from Streptococcus mutans. Infect Immun 2000, 68(4):1864-1870.

36. Tenenbaum T, Bloier C, Adam R, Reinscheid DJ, Schroten H: Adherence to and invasion of human brain microvascular endothelial cells are 
promoted by fibrinogen-binding protein FbsA of Streptococcus agalactiae. Infect Immun 2005, 73(7):4404-4409.

37. Sommer P, Gleyzal C, Guerret S, Etienne J, Grimaud JA: Induction of a putative laminin-binding protein of Streptococcus gordonii in human infective endocarditis. Infect Immun 1992, 60(2):360-365.

38. Poyart C, Quesne G, Trieu-Cuot P: Taxonomic dissection of the Streptococcus bovis group by analysis of manganese-dependent superoxide dismutase gene (sodA) sequences: reclassification of 'Streptococcus infantarius subsp. coli' as Streptococcus lutetiensis sp. nov. and of Streptococcus bovis biotype 11.2 as Streptococcus pasteurianus sp. nov. Int J Syst Evol Microbiol 2002, 52(Pt 4):1247-1255.

39. Rubens CE, Smith S, Hulse M, Chi EY, van Belle G: Respiratory epithelial cell invasion by group B streptococci. Infect Immun 1992, 60(12):5157-5163.

40. Lalonde M, Segura M, Lacouture S, Gottschalk M: Interactions between Streptococcus suis serotype 2 and different epithelial cell lines. Microbiology 2000, 146:1913-1921.

41. Dreier J, Störmer $M$, Kleesiek $K$ : Two novel real-time reverse transcriptase PCR assays for rapid detection of bacterial contamination in platelet concentrates. J Clin Microbiol 2004, 42(10):4759-4764.

42. van't Wout JW, Bijlmer HA: Bacteremia due to Streptococcus gallolyticus, or the perils of revised nomenclature in bacteriology. Clin Infect Dis 2005, 40(7):1070-1071.

43. Styriak I, Laukova A, Fallgren C, Wadstrom T: Binding of selected extracellular matrix proteins to enterococci and Streptococcus bovis of animal origin. Curr Microbiol 1999, 39(6):327-335.

44. Stipp RN, Goncalves RB, Hofling JF, Smith DJ, Mattos-Graner RO: Transcriptional analysis of $g t f B, g t f C$, and $g b p B$ and their putative response regulators in several isolates of Streptococcus mutans. Oral Microbiol Immunol 2008, 23(6):466-473.

45. Nakano K, Fujita K, Nishimura K, Nomura R, Ooshima T: Contribution of biofilm regulatory protein A of Streptococcus mutans, to systemic virulence. Microbes Infect 2005, 7(11-12):1246-1255.

46. Froeliger EH, Fives-Taylor P: Streptococcus parasanguis fimbria-associated adhesin fap1 is required for biofilm formation. Infect Immun 2001 69(4):2512-2519.

47. Kilic AO, Tao L, Zhang Y, Lei Y, Khammanivong A, Herzberg MC Involvement of Streptococcus gordonii beta-glucoside metabolism systems in adhesion, biofilm formation, and in vivo gene expression. $J$ Bacteriol 2004, 186(13):4246-4253.

48. Westerlund B, Korhonen TK: Bacterial proteins binding to the mammalian extracellular matrix. Mol Microbiol 1993, 9(4):687-694.

49. Lowrance $J H$, Baddour $L M$, Simpson WA: The role of fibronectin binding in the rat model of experimental endocarditis caused by Streptococcus sanguis. J Clin Invest 1990, 86(1):7-13.

50. Sillanpää J, Nallapareddy SR, Qin X, Singh KV, Muzny DM, Kovar CL, Nazareth LV, Gibbs RA, Ferraro MJ, Steckelberg JM, et al: A collagenbinding adhesin, Acb, and ten other putative MSCRAMM and pilus family proteins of Streptococcus gallolyticus subsp. gallolyticus (Streptococcus bovis Group, biotype I). J Bacteriol 2009, 191(21):6643-6653.

51. Edgell CJ, Haizlip JE, Bagnell CR, Packenham JP, Harrison P, Wilbourn B, Madden VJ: Endothelium specific Weibel-Palade bodies in a continuous human cell line, EA.hy926. In Vitro Cell Dev Biol 1990, 26(12):1167-1172.

52. Salasia Sl, Lammler C, Herrmann G: Properties of a Streptococcus suis isolate of serotype 2 and two capsular mutants. Vet Microbiol 1995, 45(23):151-156.

53. Rostand KS, Esko JD: Microbial adherence to and invasion through proteoglycans. Infect Immun 1997, 65(1):1-8.

doi:10.1186/1471-2180-10-78

Cite this article as: Vollmer et al: Interactions between endocarditisderived Streptococcus gallolyticus subsp. gallolyticus isolates and human endothelial cells. BMC Microbiology 2010 10:78.

\section{Submit your next manuscript to BioMed Central and take full advantage of:}

- Convenient online submission

- Thorough peer review

- No space constraints or color figure charges

- Immediate publication on acceptance

- Inclusion in PubMed, CAS, Scopus and Google Scholar

- Research which is freely available for redistribution

Submit your manuscript at www.biomedcentral.com/submit
Ciomed Central 